\title{
Papéis sexuais e hierarquias de gênero na História Social sobre infância no Brasil $^{*}$
}

\author{
Luzinete Simões Minella**
}

\begin{abstract}
Resumo
Neste artigo objetivo analisar, a partir de uma perspectiva de gênero, algumas das principais contribuições sobre infância produzidas no âmbito da História Social e da Sociologia Histórica no Brasil. Através de levantamento bibliográfico não exaustivo, examinei várias obras que se remetem às crianças nos períodos colonial e imperial, tendo rastreado e sistematizado as informações sobre o seu cotidiano. A análise se inspirou em vários aportes da epistemologia feminista e na problematização dos conceitos de infância e de criança.
\end{abstract}

Palavras-chave: Gênero, Infância, Papéis Sexuais, Estudos Histórico-Sociais.

\footnotetext{
" Recebido para publicação em março de 2005, aprovado em abril de 2006.

** Professora da Universidade Federal de Santa Catarina. luzinete@matrix.com.br
} 
História Social sobre infância no Brasil

Sex Roles and Gender Hierarchies in the Social History of Childhood in Brazil

\begin{abstract}
In this article I analyze, from the perspective of gender, some of the main contributions on childhood produced in the field of Social History and Historical Sociology in Brazil. Based on a nonexhaustive bibliographical research, I examined several works about children in the Colonial and Imperial periods, collecting and organizing information on their daily lives. The analysis was inspired by several contributions of feminist epistemology and by a problematization of the concepts of childhood and of children.
\end{abstract}

Key Words: Gender, Childhood, Sex Roles, Historical and Social Studies. 
Luzinete Simões Minella

\section{I - Introdução: o horizonte teórico da reflexão}

Este artigo analisa algumas das principais contribuições sobre a infância produzidas no âmbito da História Social e da Sociologia Histórica no Brasil, tentando compreender como as leituras elaboradas por esses campos disciplinares, na medida em que contém inúmeras referências aos papéis sexuais atribuídos aos meninos e às meninas, revelam polarizações, desigualdades $e$ hierarquias de gênero. ${ }^{1}$

Essa análise destaca algumas obras de reconhecida importância que remetem à condição infantil nos períodos colonial $e$ imperial, ressaltando as informações relativas aos hábitos $e$ padrões de socialização, às regras de sociabilidade na família, na escola, no trabalho e nas ruas. Em virtude das dificuldades encontradas para separar nitidamente as fronteiras entre História Social e Sociologia Histórica, o conjunto das obras consultadas recebe a denominação de estudos histórico-sociais.

O enfoque desse estudo se estrutura a partir de uma série de preocupações inspiradas na(s) epistemologia(s) feminista(s) dos anos 90, a partir das quais pretendo estabelecer um diálogo com a produção consultada. Tais preocupações podem ser traduzidas nas seguintes questões: quais os aspectos do cotidiano infantil considerados relevantes por esses estudos e o que "dizem" e/ou "deixam de dizer" sobre as hierarquias de gênero? Por que, ao falar sobre meninos e meninas, tais estudos privilegiaram o registro dos papéis sexuais? Em que sentido essa literatura teria privilegiado os meninos, revelando dificuldades em ressaltar a situação das meninas, favorecendo assim (mesmo que involuntariamente) sua invisibilidade? De que modo as desigualdades decorrentes do exercício desigual dos papéis

1 Esse artigo apresenta a síntese dos resultados do projeto de pesquisa intitulado "Rastreando o gênero na memória da história social sobre infância no Brasil", desenvolvido no âmbito da Linha de Pesquisa Gerações, Gênero, Etnia e Educação do Programa de Pós-Graduação em Sociologia Política da UFSC entre 2002 e 2005. 
História Social sobre infância no Brasil

sexuais foram relacionadas a outros tipos de desigualdades sociais como as de classe ou raça? Quais as razões históricas que podem explicar por que a literatura consultada não teria desenvolvido uma atitude crítica frente à rígida sexualização dos papéis e às polarizações? Em que medida os resultados dos estudos analisados podem ser submetidos a uma leitura de gênero?

Sei de antemão que será difícil responder de modo satisfatório, dentro dos limites desse artigo, a todas essas questões. É provável que algumas sejam apenas parcialmente respondidas, outras redefinidas e novas questões poderão emergir. Não obstante esta margem de imprevisibilidade, espero que os resultados possam inspirar uma reflexão a respeito do impacto das teorias feministas e dos estudos de gênero sobre a produção do conhecimento científico na área, colaborando para promover novas leituras sobre a infância.

Embora a expansão e a consolidação dessas teorias e desses estudos tenham se intensificado nas últimas décadas, são raras ainda as iniciativas que investem analiticamente nas intersecções entre gênero e infância. De acordo com o balanço preliminar da literatura sobre o tema, boa parte dessas iniciativas consiste em estudos empíricos e, dificilmente, reflexões teóricas. Tentando preencher esse tipo de lacuna, pretendo, portanto, contribuir para a construção de transversalidades entre os conceitos de infância e de gênero, estimulada, de um lado, pelos aportes da epistemologia feminista $e$ pelo debate sobre os limites $e$ as possibilidades do próprio conceito de gênero. De outro lado, pela problematização dos conceitos de infância e de criança, através da discussão da "descoberta da infância" como etapa de vida específica $e$, posteriormente, como questão pública e objeto de investigação científica.

Entendo que as tentativas no sentido dessa construção, devem partir de alguns pressupostos sobre o alcance $e$ os limites do conhecimento científico, ou seja, da crítica à ciência conforme as perspectivas de Michel Foucault, Jean-François Lyotard e da epistemologia feminista. O primeiro deles leva em conta que esse 
conhecimento, não obstante os esforços empreendidos pelos diferentes campos disciplinares, no sentido de desenvolver estratégias de investigação que assegurem resultados objetivos, não têm conseguido se livrar das ambigüidades e contradições.

Refletindo sobre a história da ciência e dos discursos, Michel Foucault afirma que

uma disciplina não é a soma de tudo o que pode ser dito de verdadeiro sobre alguma coisa; não é nem mesmo o conjunto de tudo o que pode ser aceito, a propósito de um mesmo dado, em virtude de um princípio de coerência ou de sistematicidade; [por isso mesmo, ele constata que as disciplinas] são feitas tanto de erros como de verdades, erros que não são resíduos ou corpos estranhos, mas que têm funções positivas, uma eficácia histórica, um papel muitas vezes indissociável daquele das verdades. ${ }^{2}$

O segundo pressuposto sugere que tais erros, resíduos ou corpos estranhos resultam da própria instabilidade das categorias científicas, o que levou Jean-François Lyotard a caracterizar a ciência pós-moderna como "pesquisa de instabilidade". ${ }^{3}$ De acordo com Sandra Harding, a epistemologia feminista, tem que saber conviver com essa característica, sendo capaz de "usar as próprias instabilidades como recursos de pensamento e de prática". 4

Tal constatação, bem como suas reflexões sobre os discursos patriarcais e os preconceitos androcêntricos da ciência ocidental moderna, permitem que Harding recomende que

2 Foucault, Michel. A ordem do discurso. São Paulo, Loyola, 1996, p.31.

${ }^{3}$ LYOTARD, Jean-François. O pós-moderno. Rio de Janeiro, José Olympio, 1988, p.99.

4 HARDING, Sandra. A instabilidade das categorias analíticas na teoria feminista. Revista Estudos Feministas, vol. I, n 1, 1993, pp.7-32. 
História Social sobre infância no Brasil

no exame da crítica feminista à ciência, devemos, portanto, refletir sobre tudo o que a ciência não faz, as razões das exclusões, como elas conformam a ciência precisamente através das ausências, quer sejam elas reconhecidas ou não. ${ }^{5}$

Embora a atenção de Jane Flax esteja centrada em outros eixos $-e$ portanto suas contribuições se diferenciem de vários argumentos defendidos e posteriormente reelaborados por Sandra Harding em Rethinking Standpoint Epistemology ${ }^{6}$ - na impossibilidade de aprofundar essas diferenças, ressalto algumas linhas de continuidade entre essas autoras, a partir das relações que Flax elabora entre a análise das relações de gênero, pósmodernismo e política. Tais linhas foram decisivas no sentido de nortear a conceituação do gênero que fundamenta essa investigação. Tal conceituação interpreta o gênero como algo que transcende e ao mesmo tempo inclui os papéis sexuais. De acordo com Flax,

uma meta básica da teoria feminista é (e deve ser) analisar as relações de gênero: como as relações de gênero são constituídas e experimentadas e como nós pensamos sobre elas, [pois] através do estudo do gênero, esperamos alcançar um distanciamento crítico em relação aos arranjos de gênero existentes. ${ }^{7}$

Tal distanciamento crítico se inspira, segundo a autora, no desconstrutivismo dos discursos pós-modernos e das teorias feministas em relação às crenças:

5 ID., IB., p.13.

6 ID. Rethinking Standpoint Epistemology: What is Strong "Objectivity"?. In: Alcoff, Linda \& PotTER, Elizabeth. (eds.) Feminist Epistemologies. New York, Routledge, 1993, pp.49-82.

7 FlAX, Jane. Pós-Modernismo e as Relações de Gênero na Teoria Feminista. In: Hollanda, Heloísa Buarque de. (org.) Pós-modernismo e política. Rio de Janeiro, Rocco, 1991, p.218. 
as teóricas feministas mergulham em discursos pósmodernistas e lhes fazem eco, assim que começam a desconstruir noções de razão, conhecimento ou ego $e$ a revelar os efeitos dos arranjos de gênero que se escondem por trás de fachadas "neutras" e universalizantes. ${ }^{8}$

Refletindo sobre o objeto das teorias feministas, Flax afirma que

as "relações de gênero" são uma categoria destinada a abranger um conjunto complexo de relações sociais, bem como a se referir a um conjunto mutante de processos sociais historicamente variáveis. O gênero, tanto como categoria analítica quanto como processo social é relacional. Ou seja: as relações de gênero são processos complexos e instáveis (ou "totalidades" temporárias na linguagem da dialética) constituídos por e através de partes inter-relacionadas. Essas partes são interdependentes, ou seja, cada parte não tem significado ou existência sem as outras. [Logo, o terceiro pressuposto da análise leva em conta que] as relações de gênero são divisóes e atribuiçóes diferenciadas e (por enquanto) assimétricas de traços $e$ capacidades humanos configurando-se como relaçôes de dominação. ${ }^{9}$

A partir destas colocações, compreende-se que essas atribuições terminam por assumir o caráter de representações.

A análise se fundamenta ainda numa quarta pressuposição: para entender gênero como representação, compreendendo em que medida esse campo científico também construiu representações sobre as hierarquias de gênero Teresa de Lauretis parte de uma série de quatro proposições para aprofundar sua

8 ID., IB., p.224. A autora cita como exemplos de filósofos pós-modernos, Friedrich Nietzsche, Jacques Derrida, Michel Foucault, Jacques Lacan, Richard Rorty, Paul Feyerabend, Ludwig Wittgenstein, Julia Kristeva e Jean-François Lyotard.

9 ID., IB., p.228. 
História Social sobre infância no Brasil

análise sobre aquilo que denominou de "tecnologia do gênero": gênero é uma representação que tem implicações "concretas ou reais", "sociais e subjetivas" na vida das pessoas; representar o gênero é construir o gênero e,

pode-se dizer que toda a arte e a cultura erudita ocidental são um registro da história dessa construção; a construção do gênero também se faz, embora de forma menos óbvia, na academia, na comunidade intelectual, nas práticas artísticas de vanguarda, nas teorias radicais, e até mesmo, de forma bastante marcada, no feminismo, [além de se evidenciar nos "aparelhos ideológicos de Estado"]. ${ }^{10}$

Inspirada nesses argumentos, assinalo que a literatura consultada tampouco está situada fora das representações, desde quando ela é feita por sujeitos reais e situados, também atravessados pelos estereótipos e pelas simbologias de gênero e de sexo.

No que se refere ao conceito de gênero, é evidente que o pensamento de $\mathrm{Scott}^{11}$, situado no ponto de convergência entre significativas correntes teóricas (marxismo e pós-estruturalismo), contribui decisivamente para desenhar a quinta pressuposição, na medida em que possibilita compreender tanto a consolidação quanto a variabilidade da oposição binária masculino/feminino $e$ da sexualização de papéis, enquanto conseqüências das construções culturais sobre as diferenças sexuais. Logo, diria, como representações.

${ }^{10}$ DE LauRETIS, Teresa. A tecnologia do gênero. In: HollandA, H. B. (org.) Tendências e Impasses. O feminismo como crítica da cultura. Rio de Janeiro, Rocco, 1994, p.209.

${ }^{11}$ ScOTT, Joan. Gênero: uma categoria útil de análise histórica. Educação e Realidade, Porto Alegre, vol. 20, n ${ }^{\circ}$ 2, jul-dez 1990; Prefácio a Gender and Politics of History. Cadernos Pagu (3), Núcleo de Estudos de Gênero Pagu/Unicamp, 1994; ainda sobre o pensamento de Scott, ver GROSSI, Miriam Pillar; HeIlboRn, Maria Luiza e Rial, Carmen. Entrevista com Joan Wallach Scott. Revista Estudos Feministas, vol. 6, n $1,1998$. 
Ao realizar um balanço da epistemologia feminista, Margareth Rago constata a necessidade de

reafirmar que os principais pontos da crítica feminista à ciência incidem na denúncia de seu caráter particularista, ideológico, racista e sexista: o saber ocidental opera no interior da lógica da identidade, valendo-se de categorias reflexivas incapazes de pensar a diferença.

Considerando que os conceitos científicos, conseqüentemente, resultam "identitários, portanto, excludentes", a autora afirma que "a crítica feminista evidencia as relações de poder constitutivas da produção dos saberes". ${ }^{12}$ A epistemologia feminista, a partir de uma perspectiva crítica da produção do conhecimento, rejeita um conceito universal de homem, a concepção do conhecimento "como processo racional e objetivo para se atingir a verdade pura e universal" e recusa também que as práticas masculinas sejam mais valorizadas que as femininas e, portanto, que o mundo privado seja "considerado de menor importância frente à esfera pública, no imaginário ocidental". ${ }^{13}$ Levando em conta essa linha de argumentação, tentei dialogar com os textos selecionados com um olhar atento tanto para as possíveis semelhanças com a maneira tradicional de se fazer ciência criticada pela autora, quanto com as prováveis rupturas que esta produção possa representar.

Completando o horizonte teórico da reflexão, além da inspiração nas epistemologias feministas - as quais definem $e$ dialogam com o conceito de gênero -, a análise da literatura remete à problematização dos conceitos de infância e de criança, $e$ à discussão da noção da "descoberta da infância" no Ocidente. Dentre as contribuições mais relevantes destaco a conhecida

${ }^{12}$ RAGO, Margareth. Epistemologia feminista, gênero e história. In: PEDRO, Joana Maria e Grossi, M. P. (orgs.) Masculino, Feminino, Plural. Florianópolis, Ed. Mulheres, 1998, p.25.

${ }^{13}$ ID, IB., p.32. 
História Social sobre infância no Brasil

hipótese de Philippe Ariès ${ }^{14}$ sobre o desenvolvimento do sentimento moderno de infância no âmbito da família ocidental a partir do século XVI; a definição de Colin Heywood para quem "a infância é, obviamente, uma abstração que se refere a uma determinada etapa da vida, diferentemente do grupo de pessoas sugerido pela palavra crianças". ${ }^{15}$ Abstraindo nesse momento as polêmicas entre esses autores, recupero o entendimento de Heywood sobre a criança enquanto "um constructo social que se transforma com o passar do tempo e, não menos importante, varia de acordo com os grupos sociais e étnicos de qualquer sociedade". Além disso, não obstante a biologia desempenhe um papel significativo, segundo o autor, torna-se difícil hoje pensar em termos de uma criança "natural e universal", sendo a infância, "em grande medida, o resultado da expectativa dos adultos". ${ }^{16}$ Dentre os quais, acredito, também se incluem os cientistas.

Destaco ainda o ponto de vista de Moysés Kuhlman Júnior e Rogério Fernandes, quando assinalam que

a palavra infância evoca um período da vida humana; no limite da significação, o período da palavra inarticulada, o período que poderíamos chamar de construção/apropriação de um sistema pessoal de comunicação, de signos e de sinais destinados a fazer-se ouvir, [enquanto] o vocábulo criança, por sua vez, indica uma realidade psicobiológica referenciada ao indivíduo. ${ }^{17}$

\footnotetext{
${ }^{14}$ ARIÈs, Philippe. História Social da Criança e da Família. Rio de Janeiro, Livros Técnicos e Científicos Editora, 1981.

${ }^{15}$ HeYwood, Colin. Uma História da Infância. Porto Alegre, Artmed Editora, 2004, p.22.

${ }^{16}$ ID, IB., p.21.

${ }^{17}$ KuHLmann Junior, Moysés e FERnANDES, Rogério. Sobre a história da infância. In: FARIA FILHO, Luciano Mendes de. (org.) A infância e sua educação - materiais, práticas e representações (Portugal e Brasil). Belo Horizonte, Autêntica, 2004, p.16.
} 
As advertências desses autores, sem dúvida, instrumentaram um tipo de análise que não esperou da literatura consultada uma coerência absoluta. O esforço dessa investigação se concentrou, portanto, numa compreensão sobre o processo do conhecimento enquanto ação circunstanciada baseada em coordenadas flexíveis o suficiente para incluir e excluir aspectos da realidade, "falando" através desses procedimentos.

\section{II - História social da infância no Brasil: papéis sexuais revelam hierarquias de gênero}

O levantamento bibliográfico sobre a história social da infância no Brasil incluiu várias obras que remetem aos períodos colonial e imperial. Instruída a partir das recomendações e das questões levantadas no item anterior, a análise dessas obras configurou-se como uma tentativa de leitura de gênero sobre a infância, que tem seus limites porque através delas puderam ser rastreadas e sistematizadas apenas as informações que constituíram o foco dos/as historiadores/as: aquelas relativas ao cotidiano $e$ aos padrões de sociabilidade de meninos e meninas na família, na escola, no trabalho, nos jogos e brincadeiras, etc. Dessa forma, a leitura de gênero privilegiou os fragmentos que evidenciam mais explicitamente o modo como os papéis sexuais reforçam desigualdades e hierarquias. Reconheço que o período consultado é demasiado amplo e que se refere a crianças em situações distintas. Sei também que vários estudos exigiriam análises específicas, no entanto, dentro dos limites desse artigo, tentei possibilitar uma visão mais geral do problema. Reflexões sobre masculinidade e feminilidade, mereceriam sem dúvida, um estudo à parte.

As obras consultadas incluem as pesquisas de Maria Luiza Marcílio sobre a emergência da infância carente como questão pública e a evolução dos modelos assistenciais ${ }^{18}$; a etnografia

${ }^{18}$ MARCílio, Maria Luiza. A roda dos expostos e a criança abandonada na História do Brasil. 1726-1930. In: FreITAS, Marcos Cezar de. (org.) História Social 
História Social sobre infância no Brasil

sobre a formação da infância na sociedade brasileira realizada por Gilberto Freyre, através do registro do cotidiano das casas grandes, senzalas, aldeias indígenas escolas criadas pelos jesuítas ${ }^{19}$; a análise de Miriam Moreira Leite sobre os livros de viagem dos viajantes estrangeiros que estiveram no Brasil entre 1803 e $1900 .^{20}$

São também tratados vários estudos que compõem a publicação organizada por Mary Del Priore: as análises de Martha Abreu sobre a estigmatização das meninas pobres e de Raquel Zumbano Altman sobre os brinquedos e jogos de crianças indígenas e portuguesas; a pesquisa de Rafael Chambouleyron acerca do papel dos jesuítas na formação dos meninos indígenas e portugueses e de Mary Del Priore sobre o cotidiano da criança livre no Brasil entre os períodos colonial e imperial; a reconstituição das memórias sobre a infância na Amazônia nas primeiras décadas do século XX conforme o depoimento de alguns literatos, elaborada por Aldrin Moura de Figueiredo; os relatos sobre a vida diária das crianças escravas e das crianças da elite imperial, sistematizados por José Roberto de Góes com Manolo Florentino e por Ana Maria Mauad, respectivamente; as contribuições de Esmeralda Blanco B. de Moura acerca das crianças operárias no contexto da metrópole; de Fábio Pestana Ramos sobre a vida trágica das crianças nas embarcações portuguesas durante o século XVI; e por último, de Renato Pinto Venâncio sobre os aprendizes da Marinha. ${ }^{21}$

da Infância no Brasil. São Paulo, Cortez, 1997, pp.51-76; e História Social da Criança Abandonada. São Paulo, Hucitec, 1998.

${ }^{19}$ Freyre, Gilberto. Casa Grande \& Senzala. 42a . ed. Rio de Janeiro/São Paulo, Record, 2001.

${ }^{20}$ LEITE, Miriam L. Moreira. A infância no século XIX segundo memórias e livros de viagem. In: FreitAS, M.C. (org.) História Social da Infância... Op. cit., pp.1750 .

${ }^{21}$ ABREU, Martha. Meninas perdidas; Altman, Raquel Zumbano. Brincando na história; CHAmBOULEYRON, Rafael. Jesuítas e as crianças no Brasil quinhentista; Del PRIORE, M. O cotidiano da criança livre no Brasil entre a Colônia e o 
São ainda consideradas algumas das pesquisas que constam em publicação organizada por Francisco Pilotti e Irene Rizzini. Nesse caso, resgatei a história das políticas sociais e da legislação sobre infância, realizada por Esther Maria de M. Arantes ao tratar o ensino religioso $e$ as políticas higienistas; as perspectivas de trabalho das crianças $e$ adolescentes pobres, elaborada por Eva Terezinha S. Faleiros e a contribuição de Irma Rizzini sobre os modelos de assistência implantados na segunda metade do século $\mathrm{XIX}^{22}$

No caso da história da infância brasileira no período colonial, a literatura mencionada destaca inicialmente a participação dos jesuítas, na medida em que estes capitanearam os primeiros projetos pedagógicos voltados para a infância. De cunho religioso, tais projetos se baseavam numa literatura de conversão, tendo incidido durante o século $\mathrm{XVI}$, principalmente sobre os meninos de origem indígena, embora tenha incluído também menos regularmente, as crianças mestiças e portuguesas.

De acordo com o estudo de Chambouleyron, o aprendizado da doutrina dava-se principalmente através da memorização e era complementado pela transmissão dos "bons costumes", pelo ensino da música e do canto, através de um rígido sistema

\footnotetext{
Império; FIGUEIREDO, Aldrin Moura de. Memórias da Infância na Amazônia; GÓES, José Roberto de e FLORENTINO, Manolo. Crianças escravas, crianças dos escravos; MAUAD, Ana Maria. A vida das crianças da elite durante o Império; MOURA, Esmeralda Blanco Bolsonaro de. Crianças Operárias na recémindustrializada São Paulo; RAMOs, Fábio Pestana. A história trágico-marítima das crianças nas embarcações portuguesas do século XVI; VENÂNCIO, Renato Pinto. Os aprendizes da guerra. In: DEL PRIORE, Mary. (org.) História das Crianças no Brasil. São Paulo, Contexto, 1999.

${ }^{22}$ ARANTES, Esther Maria de Magalhães. Rostos de Crianças no Brasil; FALEIROS, Eva Teresinha Silveira. A criança e o adolescente. Objetos sem valor no Brasil Colônia e no Império; RIzzINI, Irma. Meninos desvalidos e menores transviados. In: PilotTi, Francisco e RizzinI, Irene. (orgs.) $A$ arte de governar crianças. $A$ história das políticas sociais, da legislação e da assistência à infância no Brasil. Rio de Janeiro, Instituto Interamericano Del Nino/Editora Universitária Santa Úrsula/Amais Livraria e Editora, 1995.
} 
História Social sobre infância no Brasil

disciplinar "que dependia de uma vigilância constante, da delação e dos castigos corporais". ${ }^{23}$

$\mathrm{O}$ autor afirma que os meninos eram escolhidos porque estariam prontos, na visão dos jesuítas, para receber os preceitos de uma nova fé, sem impor as resistências que certamente seriam encontradas nos adultos. ${ }^{24}$

Mas o cotidiano das crianças indígenas, também era feito de brincadeiras. Os resultados da pesquisa de Altman mostram que durante uma brincadeira e outra, as meninas indígenas brincavam com bonecas de barro e madeira e acompanhavam as mães nos seus afazeres: "cuidar das plantações, colher e trazer legumes em suas canastras, cozer a mandioca, fazer a farinha, cuidar dos irmãos a quem carregam às costas numa tipóia, balançar a rede", além de nadar, pescar e participar de vários jogos fazia parte de sua rotina. ${ }^{25}$

Um dos jogos mencionados pela autora, intitulado "casamento", oferece algumas pistas sobre as desigualdades de gênero:

formam-se uma fila de meninos e uma fila de meninas, frente a frente. A primeira menina pergunta ao primeiro menino, apontando a sua vizinha: "queres casar com ela?". Ele responde: "Não, pois é muito feia" ou outro atributo indelicado, e assim, segue o jogo até chegar à última menina. Respondendo "sim", o menino troca de lugar com esta menina, o jogo recomeça até que todos tenham trocado de lugar e a brincadeira continua até cansar, sempre no meio de muitas gargalhadas. ${ }^{26}$

\footnotetext{
${ }^{23}$ Chambouleyron, R. Jesuítas e as crianças... Op. cit., p.69.

${ }^{24}$ ID., IB., p.58.

${ }^{25}$ Altman, R. Z. Brincando na história. Op. cit., p.234.

${ }^{26}$ ID., IB., p. 240.
} 
As páginas da clássica obra de Gilberto Freyre, Casa Grande \& Senzala, desvendam também algumas das peculiaridades do cotidiano do menino indígena, enfatizando os aspectos lúdicos que prevaleciam antes da colonização, através dos jogos de azar, jogos com bolas de borracha assimilados dos europeus, o canto $e$ dança.

Detalhando as informações sobre o cotidiano, e informando mais claramente sobre as hierarquias de gênero, o autor aponta que o menino das tribos indígenas "crescia livre dos castigos corporais e de disciplina paterna ou materna. Entretanto, a meninice não deixava de seguir uma espécie de liturgia ou ritual, como aliás toda a vida do primitivo". Tendo os cabelos cortados, ao alcançar a puberdade o menino era segregado nos "clubes ou casas secretas dos homens, chamadas baito entre as tribos do Brasil Central". Nesta fase da vida, "processava-se uma verdadeira educação moral e técnica do menino; o seu preparo para as responsabilidades e privilégios de homem"; esta educação incluía as noções de construção, de caça, pesca, técnicas de guerra, canto, música, magia e religião. ${ }^{27}$

Essa segregação, segundo o autor,

parece que visava assegurar ao sexo masculino o domínio sobre o feminino: educar o adolescente para exercer esse domínio. Eram casas vedadas às mulheres (a não ser as velhas, masculinizadas ou dessexualizadas pela idade) $e$ aos meninos, antes de iniciados. Nelas se guardavam as gaitas e os maracás que mulher nenhuma se lembrasse de querer avistar mesmo de longe; significava a morte certa. Durante a segregação o menino aprendia a tratar a mulher de resto; a sentir-se sempre superior a ela; a abrir-se em intimidades não com a mãe nem com mulher nenhuma, mas com o pai $e$ os amigos. ${ }^{28}$

${ }^{27}$ FreYRe, G. Casa Grande \& Senzala. Op. cit., p.205.

${ }^{28}$ ID., IB., p. 205. 
História Social sobre infância no Brasil

Nos estudos consultados sobre a expansão no século XVI, existe um consenso sobre as iniciativas de conversão jesuítica, admitindo-se que vários orfanatos, casas e colégios foram criados nas diferentes capitanias da Coroa, visando a catequese das crianças. Nestas instituições os meninos, além de aprender a ler, escrever e contar, tinham aulas de teologia, cursos de artes, latim, participavam das procissões, das recepções às autoridades, de encenações religiosas. De acordo com Altman, a inclinação dos indígenas para o canto impressionava os jesuítas, favorecendo a criação dos coros dos meninos que levavam em suas iniciativas de catequese: "entram pelas povoações, as crianças à frente, entoando as ladainhas e outras crianças rapidamente se agregam ao séquito, pulando, cantando, dançando". ${ }^{29}$

Freyre afirma que "os colégios dos jesuítas nos primeiros dois séculos, depois os seminários e os colégios de padre, foram os grandes focos de irradiação de cultura no Brasil colonial”. Nos séculos XVI e XVII uma população infantil heterogênea se reunia nos colégios de padres:

filhos de caboclos arrancados aos pais; filhos de normandos encontrados nos matos; filhos de portugueses; mamelucos; meninos órfãos vindos de Lisboa. Meninos louros, sardentos, pardos, morenos, cor de canela. Só negros e muleques parecem ter sido barrados das primeiras escolas jesuíticas. $^{30}$

Tal interpretação sobre o papel dos jesuítas coincide com os comentários de Arantes:

construindo casas e colégios, atraindo para junto de si os filhos dos índios e dos mestiços, amparando órfãos portugueses e brasileiros, ocupando-se das famílias e dos

${ }^{29}$ Altman, R. Z. Brincando na história. Op. cit., p.241.

${ }^{30}$ Freyre, G. Casa Grande \& Senzala. Op. cit., p.466. 
Luzinete Simões Minella

filhos dos portugueses, foram os jesuítas, por mais de 200 anos os educadores do Brasil. ${ }^{31}$

A respeito dos órfãos e órfãs portugueses, Ramos aponta para alguns aspectos dignos de nota sobre as diferenças entre os destinos de meninos e meninas. Ao reconstituir o que chama de "história trágico-marítima das crianças nas embarcações portuguesas do século XVI", o autor afirma que

enquanto os meninos pobres menores de 16 anos eram embarcados como grumetes e pagens nas naus portuguesas do século XVI, e alguns dos filhos dos oficiais, mesmo não sendo pagens, embarcavam simplesmente como acompanhantes de seus pais a fim de aprender seu ofício, as meninas órfãs de pai e pobres eram arrancadas a força de suas famílias e embarcadas sob a categoria "órfãs do Rei". ${ }^{32}$

Consulta a várias fontes históricas permite ao autor sugerir que, devido à falta de mulheres brancas nas colônias portuguesas, meninas pobres eram seqüestradas dos orfanatos de Lisboa $e$ Porto para servir de companhia para os homens solteiros da baixa nobreza portuguesa.

Sobre as dificuldades enfrentadas por meninos e meninas nessas viagens, numa clara alusão aos papéis sexuais, o autor conclui:

em uma época em que meninas de 15 anos eram consideradas aptas para casar e meninos de nove anos plenamente capacitados para o trabalho pesado, o cotidiano infantil a bordo das embarcações portuguesas era extremamente penoso para os pequeninos. Os meninos não eram ainda homens mas eram tratados como se fossem, e ao mesmo tempo eram considerados pouco mais

${ }^{31}$ Arantes, E. M. M. Rostos de Crianças no Brasil. Op. cit., p.183.

${ }^{32}$ RAmos, F. P. A história trágico-marítima das crianças... Op. cit., p.32. 
História Social sobre infância no Brasil

que animais cuja mão-de-obra deveria ser explorada enquanto durasse sua vida útil. As meninas de 12 a 16 anos não eram ainda mulheres, mas em idade considerada casadoura pela Igreja Católica, eram caçadas e cobiçadas como se o fossem. Em meio ao mundo adulto, o universo infantil não tinha espaço: as crianças eram obrigadas a se adaptar ou perecer. ${ }^{33}$

Até esta fase, alguns autores consideram que a infância ainda não ultrapassara os domínios da vida privada. Segundo Leite, por exemplo, a infância

passa a ser "visível" quando o trabalho deixa de ser domiciliar e as famílias, ao se deslocarem e dispersarem, não conseguem mais administrar o desenvolvimento dos filhos pequenos. [Neste momento] as crianças transformamse em "menores" e como tal rapidamente congregam as características de abandonados e delinqüentes. ${ }^{34}$

Marcílio afirma que a partir do século XVI a situação das crianças carentes emerge como questão social no Ocidente, originando ações filantrópicas por parte de entidades ligadas à Igreja (confrarias, obras pias e grêmios). Mais adiante, no século XVIII, começam a surgir na França obras resultantes apenas da iniciativa privada, sem finalidade missionária. Esse período, interpretado pela autora como "o século da criança na Europa", assistiu ao avanço da industrialização e da urbanização, bem como à expansão do Estado através, dentre outros mecanismos, das políticas sociais. ${ }^{35}$ Nessa fase, as crianças, antes abandonadas nas ruas, nas igrejas e nos conventos, passam a ser deixadas nos hospícios de expostos, tendo as Rodas de Expostos se expandido

\footnotetext{
${ }^{33}$ ID., IB., p. 48.

${ }^{34}$ LEITE, M. L. M. A infância no século XIX... Op. cit., p.18.

${ }^{35}$ Marcílıo, M. L. História Social da Criança Abandonada. Op. cit., p.75.
} 
pelos países europeus até o final do século XIX, quando então foram extintas, dando lugar a novas iniciativas na área. ${ }^{36}$

Essas novas iniciativas incluíram na França do século XIX o sistema de assistência domiciliar para as mães, a criação de creches, a educação profissionalizante, os modelos preventivos de saúde, promovendo o aleitamento $e$ as vacinas, e favorecendo a elaboração e o cumprimento de normas sanitárias, dentre outras iniciativas de peso no âmbito das políticas sociais. ${ }^{37}$

Segundo a autora, no decorrer do século XIX, à exemplo do que ocorreu na França, nos demais países foram sendo estabelecidas "as conexões entre assistência pública, a Justiça de menores, a Medicina e a Psiquiatria", tendo-se gradativamente "profissionalizado" o atendimento às crianças abandonadas. ${ }^{38}$

No Brasil, durante um século, de acordo com os resultados das pesquisas realizadas pela autora, as Rodas de Expostos das Santas Casas de Misericórdia, foram as únicas instituições de amparo (temporário) das crianças abandonadas no país, não obstante as irregularidades $e$ a insalubridade de suas instalações $e$ de suas práticas. No extenso e criterioso levantamento de dados coordenado por Marcílio, foram identificadas treze Rodas, situadas em diferentes cidades brasileiras, iniciadas em 1726 em Salvador, expandindo-se gradativamente para o Rio de Janeiro, Recife, São Paulo, Porto Alegre, Rio Grande, Pelotas, Cachoeira (BA), Olinda, Campos (RJ), Vitória, Desterro (SC) e Cuiabá. ${ }^{39}$

Sem condições de asilar por longos períodos os expostos, as Santas Casas estimulavam que as amas-de-leite adotassem as crianças, contribuindo com uma pequena quantia para o seu sustento e, além disso, buscavam

\footnotetext{
${ }^{36}$ ID., IB., p. 79.

${ }^{37}$ ID., IB., p.81.

${ }^{38}$ ID., IB., p.86.

${ }^{39}$ ID., IB. A roda dos expostos... Op. cit., p.64.
} 
História Social sobre infância no Brasil

casas de familias que pudessem receber as crianças como aprendizes - no caso dos meninos - de algum ofício ou ocupação (ferreiro, sapateiro, caixeiro, balconista, etc.) e, no caso das meninas como empregadas domésticas. Para os meninos, havia ainda a possibilidade de serem enviados para as Companhias de Aprendizes Marinheiros ou de Aprendizes do Arsenal de Guerra, verdadeiras escolas profissionalizantes dos pequenos desvalidos, dentro da dura disciplina militar. ${ }^{40}$

Comenta a autora que as meninas, devido à preservação da honra e castidade, eram alvo de maiores preocupações pela Santa Casa. Por isto mesmo, para elas foram criadas junto às maiores Misericórdias um Recolhimento de meninas órfãs e desvalidas que estiveram sempre muito ligadas às casas de expostos". Entre os séculos XVIII e XIX foram criadas várias instituições asilares, umas mistas, outras exclusivamente para meninos com ênfase no ensino profissionalizante e nos preceitos morais. E ainda, outras para meninas com ênfase na educação doméstica e religiosa, surgindo a filantropia como novo modelo assistencial que substituiria o modelo da caridade. ${ }^{41}$

Constatação semelhante é encontrada no estudo de Faleiros: o futuro das crianças pobres,

após os 7 anos dependia, em grande parte, da família que as criavam; os meninos podiam ser encaminhados aprendizes de algum ofício, caixeiros de loja, seminários. As meninas realizavam trabalhos domésticos em troca do sustento ou eram encaminhadas à Casa de Recolhimento (onde recebiam dotes para o casamento). ${ }^{42}$

\footnotetext{
${ }^{40}$ ID., IB., p.74.

${ }^{41}$ ID., IB., pp.74-75.

${ }^{42}$ FAleiros, E. T. S. A criança e o adolescente... Op. cit., p.231.
} 
Seguindo a tendência manifestada nos países europeus, médicos higienistas, juristas e ações coordenadas pelo Estado, agirão no sentido de extinguir as Rodas, as quais sobreviveram ainda por muito tempo, tendo em vista uma série de fatores ligados à incapacidade dos poderes públicos para resolver a questão. Segundo Venâncio, a extinção das Rodas se explica entre outros fatores devido ao alto índice de mortalidade infantil, decorrente da precariedade da dieta alimentar, e dos problemas infra-estruturais peculiares aos asilos da época: falta de ventilação, umidade, excesso de população, falta de acompanhamento médico, etc. ${ }^{43}$

Durante o período imperial, a documentação levantada por Rizzini constata que

as primeiras medidas efetivas dos poderes públicos com relação à infância pobre surgiram na segunda metade do século XIX, destinadas à proteção dos "meninos desvalidos", excluídos os escravos e as meninas. ${ }^{44}$

De acordo com a autora, entre a segunda metade do século XIX e o início do século XX, as instituições de assistência proliferaram dando origem a vários modelos e denominações. Não era raro que os meninos pobres fossem identificados e tratados como delinqüentes, freqüentando Colônias e Escolas Correcionais $e$ Institutos Disciplinares. Projetadas para os meninos, estas instituições começam a reservar um espaço também para as meninas. Em alguns casos, elas mereciam uma atenção especial, sendo instaladas em casa à parte.

Sobre essa distribuição, Santos menciona que, em geral,

as meninas eram mantidas numa ala especial, completamente isolada e incomunicável com a ala masculina, onde basicamente predominavam as mesmas

${ }^{43}$ VenÂNCIO, R. P. Os aprendizes da guerra. Op. cit., p.196.

${ }^{44}$ RizzinI, Irma. Meninos desvalidos... Op. cit., p.244. 
História Social sobre infância no Brasil

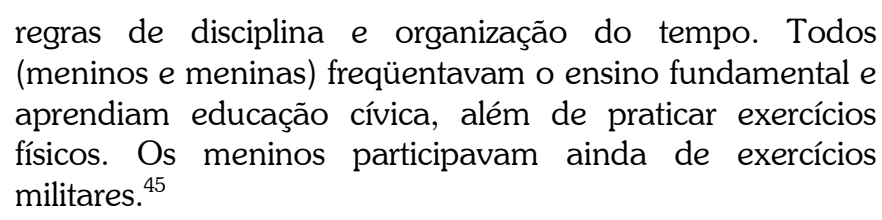

Certamente, uma história mais detalhada da distribuição de meninas e meninos nestes espaços institucionais, revelaria outros aspectos importantes das hierarquias de gênero.

De acordo com o mesmo autor, o código penal não estabelecia qualquer distinção entre meninos $e$ meninas "imputando-lhes penas idênticas para os mesmos crimes", originando, no início do século $\mathrm{XX}$, algumas críticas por parte de juristas, as quais se fundamentavam no argumento da fragilidade feminina. ${ }^{46}$

Sobre a fase da filantropia, mais especificamente entre 1854 e início do século XX, em obra posterior, Marcílio identifica em torno de quinze instituições asilares mantidas principalmente por religiosos e irmãs de caridade, que se disseminaram por diferentes capitais do país. De acordo com os dados levantados pela autora, as atividades de formação proporcionadas por tais instituições refletiam e reforçavam o ordenamento social mais geral, tal como ocorrera anteriormente nas Rodas: meninos recebiam no geral, uma formação de artífices, alfaiates, serralheiros, marceneiros, carpinteiros, sapateiros, lavradores, etc, enquanto meninas aprendiam com as irmãs de caridade, a bordar, lavar e exercer outras atividades domésticas, preparando-se para serem "boas mães". 47

De modo geral, para a autora, estas instituições filantrópicas se inspiravam principalmente nas teorias higiênicas de

\footnotetext{
45 SANTOS, Marco Antonio Cabral dos. Criança e criminalidade no início do século. In: Del PRIORE, M. (org.) História das Crianças... Op. cit., p.227.

${ }^{46}$ ID., IB., p.217.

${ }^{47}$ Marcílıo, M. L. História Social da Criança Abandonada. Op. cit., pp.191-223.
} 
normatização, nas teorias criminológicas de Lombroso e nas teorias sociológicas de cunho positivista:

seguindo princípios higiênicos e disciplinares, médicos e juristas criaram um verdadeiro projeto prisão-modelo para os menores carentes e infratores, de acordo com os valores $e$ as normas científicas propostos pelo filantropismo, segundo os quais, os meios fundamentais de recuperação eram a educação, o trabalho $e$ a disciplina. ${ }^{48}$

Arantes destaca o caráter religioso destas obras através da análise do registro dos seus objetivos vinculados não apenas ao ensino religioso, mas também às políticas higienistas da época. Por exemplo, os anais do Asilo Agrícola Santa Isabel, criado em 1886, mencionam que esta obra era destinada

\begin{abstract}
a meninos vagabundos ou destituídos de amparo da família, que aí receberão educação moral e religiosa, instrução primaria, elementos de instrução profissional, ensino agrícola de caráter prático. ${ }^{49}$
\end{abstract}

O Asilo Bom Pastor, fundado em 1914, por sua vez, mantinha a ideologia difundida no século XIX, admitindo que seu objetivo era "promover a regeneração das mulheres que se desviaram do caminho do bem e da virtude"; enquanto isso o Asilo Nossa Senhora do Amparo afirmava que pretendia "educar as meninas em misteres domésticos, preparando mães de família cristãs". O caráter duplamente discriminatório, do ponto de vista social e étnico, aparece claramente na proposta do Asilo Órfãs Brancas do Colégio Imaculada Conceição, fundado em 1864, que objetivava proporcionar "formação religiosa, moral e prática de boas empregadas domésticas e donas de casa". O Orfanato Santa Maria, fundado em 1872, à semelhança de outros tantos da época,

${ }^{48}$ ID., IB., p.218.

${ }^{49}$ ARAnTES, E. M. M. Rostos de Crianças no Brasil. Op. cit., p.219. 
História Social sobre infância no Brasil

dedicava-se à "formação de empregadas domésticas e semelhantes para meninas de cor" ${ }^{50}$

Complementando estas informações de Arantes, Faleiros adverte que

nem todas as crianças pobres eram expostas. O sistema de compadrio e a doação/adoção de crianças eram outras formas adotadas pelos pais pobres para protegerem seus filhos. Havia uma preocupação em proteger e casar donzelas, órfãs, virtuosas, filhas de legítimo casamento, cristãs velhas e brancas, como também enjeitadas. Com este fim foram fundadas Casas de Recolhimento mantidas pela Misericórdia da Bahia (1726) e do Rio de Janeiro (1740), a primeira 10 anos antes da Roda e a segunda 2 anos após a criação da Roda. ${ }^{51}$

Contribuindo para o entendimento das hierarquias étnicas que se estabeleciam entre pessoas de um mesmo sexo, durante o período escravocrata, Freyre relata que as crianças negras se transformavam numa espécie de brinquedo das crianças brancas. Remetendo-se a várias fontes históricas, ele observa que no cotidiano das grandes fazendas, os meninos negros cresciam junto com os meninos brancos e se transformavam em suas vítimas: eram o cavalo de montaria, o leva-pancadas, os criados, bois de carro, etc. ${ }^{52}$ Altman:

Situações semelhantes foram encontradas no estudo de

meninos e meninas brancas recebem de suas yayás toda sorte de mimos $e$, assistindo abertamente aos castigos reservados aos escravos, assumem também tendências sádicas, divertindo-se em brincadeiras maldosas com as

\footnotetext{
${ }^{50}$ ID., IB., p.196.

${ }^{51}$ Faleiros, E. T. S. A criança e o adolescente... Op. cit., p.225.

${ }^{52}$ Freyre, G. Casa Grande \& Senzala. Op. cit.
} 
outras crianças da casa e já não só com seus muleques. Jogando pião, sempre tem alguém que interrompa o rodopio; soltando o papagaio lá está enfiada nas tiras do rabo de brinquedo, uma lasca de vidro que acabará por cortar-lhe o rabo, fazendo-o embicar para o chão. Das brincadeiras maldosas é com o "jogo do beliscão", o "jogo de belilisco", em que, formada uma roda, acabam em geral as meninas, ao fim da cantoria, por receber um forte beliscão ou um bolo bem dado. ${ }^{53}$

Vários relatos semelhantes encontrados em Freyre indicam que não era diferente a relação das meninas brancas com as meninas negras.

Meninas brancas ou sinhazinhas eram obrigadas a ostentar os distintivos de sua posição social, principalmente nas grandes ocasiões. A descrição de Freyre do dia da primeira comunhão é ilustrativa:

desde o dia da primeira comunhão que deixavam as meninas de ser crianças: tornavam-se sinhá-moças. Era um grande dia. Maior só o do casamento. Vestido comprido todo de cassa guarnecido de folhos e pregas. O corpete franzido. A faixa de fita azul caindo para trás, em pontas largas, sobre o vestido branco. A bolsa esmoleira de tafetá. $\mathrm{O}$ véu de filó. A capela de flor de laranja. Os sapatinhos de cetim. As luvas de pelica. O livrinho de missa encadernado em madrepérola. O terço, de cordãozinho de ouro. Cruz também de ouro. ${ }^{54}$

Segundo o autor sugere, prontas e sacramentadas estavam elas então para os casamentos precoces, para ter muitos filhos $e$ envelhecer rapidamente.

${ }^{53}$ Altman, R. Z. Brincando na história Op. cit., p.244.

${ }^{54}$ Freyre, G. Casa Grande \& Senzala. Op. cit., p.399. 
História Social sobre infância no Brasil

Sintetizando informações contidas em diferentes registros feitos por viajantes (cartas e diários principalmente), Freyre assinala:

os viajantes que aqui estiveram no século XIX são unânimes em destacar este ridículo da vida brasileira: os meninos, uns homenzinhos à força desde os nove ou dez anos. Obrigados a se comportarem como gente grande: o cabelo bem penteado, às vezes frisado à Menino Jesus; o colarinho duro; calça comprida; roupa preta; botinas pretas; o andar grave; os gestos sisudos; um ar tristonho de quem acompanha enterro..$^{55}$

O estudo de Leite também aborda os livros de viagem dos estrangeiros, mas inclui, ainda, as memórias de algumas crianças que sabiam ler e escrever durante o século XIX. O autor encontra registros sobre a condição dos meninos no mercado de escravos, bem como sobre as relações de familiaridade que se estabeleciam entre crianças brancas e escravas, destacando algumas considerações anotadas por uma viajante inglesa:

no Brasil não existem crianças no sentido inglês. A menor menina usa colares e pulseiras e os meninos de oito anos fumam cigarros. Encontrei um bando de meninos voltando da escola, uma tarde. Um pequeno de aparentemente sete anos de idade tirou do bolso um maço de cigarros $e$ ofereceu a um de cada vez. Ninguém demonstrou qualquer desaprovação de um menino tão pequeno estar fumando. A linguagem desses meninos é terrível, embora eu precise admitir que, como os cocheiros de Londres, não percebem que estão usando expressões chulas. ${ }^{56}$

Pesquisas recentes realizadas no âmbito da História Social reconstituem alguns aspectos sobre o cotidiano de crianças

${ }^{55}$ ID., IB., p. 465.

${ }^{56}$ LeITE, M. L. M. A infância no século XIX... Op. cit., p.37. 
oriundas de diferentes segmentos sociais no decorrer da história da sociedade brasileira: trabalhadoras, da elite, escravas, crianças dos segmentos urbanos de baixa renda. $\mathrm{Na}$ impossibilidade de levar em conta todos os estudos, serão analisados alguns exemplos que podem contribuir mais diretamente para esclarecer as preocupações teóricas do presente trabalho.

Analisando a condição das moças pobres entre o final do século XIX e o início do século XX, e explorando particularmente a vinculação entre o seu comportamento e a jurisprudência, Abreu esclarece que a expressão "meninas perdidas" era utilizada para designar as menores de idade que haviam perdido a virgindade, as que haviam sido abandonadas, que não tinham educação, fatores que facilitavam a incorporação de instintos perversos $e$ o ingresso num mundo viciado. Verificando a documentação histórica disponível, ela constata o viés de gênero das autoridades competentes na medida em que segundo eles, aquele meio viciado, juntamente com a

devassidão dos costumes, os instintos perversos, a falta de honra e de educação, a inclinação à malícia e à liberalidade foram expressões que marcaram os julgamentos de médicos, juristas, membros do clero, literatos e jornalistas sobre as moças pobres, negras e brancas, principalmente ao longo dos últimos 150 anos de nossa história. ${ }^{57}$

Fundamentado em criteriosa pesquisa de documentos históricos, o estudo de Góes e Florentino sobre crianças escravas aponta que

entre os cativos do Brasil predominavam os adultos, poucos dos quais chegavam aos cinqüenta anos de idade. $\mathrm{O}$ desequilíbrio entre os sexos variava segundo as flutuações do tráfico, e em tempos de grandes desembarques, chegava

${ }^{57}$ ABREU, M. Meninas perdidas... Op. cit., p.289. 
História Social sobre infância no Brasil

a haver sete homens para cada três mulheres. Na média, as crianças representavam apenas dois entre dez cativos. ${ }^{58}$

Sujeitas a elevados índices de mortalidade, a população infantil era adestrada pelos seus senhores e senhoras:

por volta dos 12 anos o adestramento que as tornava adultos estava se concluindo. Nesta idade, os meninos e as meninas começavam a trazer uma profissão por sobrenome: Chico Roça, João Pastor, Ana Mucama. Alguns haviam começado muito cedo. ${ }^{59}$

Os arquivos consultados pelos autores evidenciam que meninos se dedicavam também às tarefas domésticas nas fazendas, além de cuidar do gado, colher e plantar, enquanto as meninas aprendiam a costurar e a cozinhar num contexto que incluía em relação a ambos o permanente uso da violência, o castigo e o suplício. Sobre as condições do mercado de trabalho os autores ressaltam que "ao iniciar-se no servir, lavar, passar, engomar, remendar roupas, reparar sapatos, trabalhar em madeira, pastorear e mesmo em tarefas próprias do eito, o preço crescia. O mercado valorava as habilidades que aos poucos se afirmavam" enquanto o trabalho ia ocupando uma margem de tempo cada vez maior no cotidiano das crianças. ${ }^{60}$

Bem diferente deste processo de adestramento da capacidade de trabalho, era a vida das crianças da elite. Conforme pesquisa realizada por Mauad, as crianças da elite tinham acesso, dentre outros, a brinquedos, educação e médicos especializados. A análise de documentos do século passado relativos à educação da família imperial, permite compreender, segundo a autora, que a partir de uma certa idade, quando ultrapassavam os limites das relações com as suas mães e com as suas amas de leite, "tanto em

\footnotetext{
${ }^{58}$ GóEs, J. R. e FloREntino, M. Crianças escravas... Op. cit., p.178.

${ }^{59}$ ID., IB., p. 184.

${ }^{60}$ ID., IB.
} 
termos de educação como de instrução, meninos e meninas eram tratados de forma distinta", tendo-se originado "uma educação para meninos, ministrada por homens e uma para meninas, ministrada por mulheres". ${ }^{61}$

A diferença entre as duas formas de educar, segundo a autora, residiria

basicamente na valorização dos atributos manuais $e$ intelectuais, sendo os primeiros concernentes ao universo feminino e o segundo ao masculino, mas também no tempo de duração da instrução. Os meninos da elite iam para a escola aos sete anos e só terminavam sua instrução, dentro ou fora do Brasil, com um diploma de doutor, geralmente de advogado. [Além disso] os meninos tinham uma opção alternativa aos colégios particulares, podendo optar por uma formação militar. [Os colégios passam a fazer parte das aspirações das famílias] a partir da segunda metade do XIX, também nas fazendas, os pais poderiam instruir seus filhos nos colégios, em vez de mantê-los em casa, com uma preceptora; mas tal escolha só era feita a partir dos sete anos de idade. ${ }^{62}$

\section{De acordo com Freyre,}

até meados do século XIX, quando vieram as primeiras estradas de ferro, o costume nos engenhos foi fazerem os meninos os estudos em casa, com o capelão ou com mestre particular. As casas-grandes tiveram quase sempre sala-deaula, e muitas até cafua para o menino vadio que não soubesse a lição. Muitas vezes aos meninos se reuniam crias e muleques, todos aprendendo juntos a ler e escrever; a contar $e$ a rezar. Noutros engenhos cresceram em igual ignorância meninos e muleques. ${ }^{63}$

${ }^{61}$ MAUAD, A. M. A vida das crianças da elite... Op. cit., p.152.

${ }^{62}$ ID., IB.

${ }^{63}$ Freyre, G. Casa Grande \& Senzala. Op. cit., p.466. 
História Social sobre infância no Brasil

Eram denominados "muleques" as crianças do sexo masculino que tinham entre sete $e$ doze anos $e$ se encarregavam de pequenas tarefas para os seus senhores/as: levar e trazer recados, carregar pertences, ajudar nas compras, etc.

A propósito das meninas, Mauad afirma que sua instrução também variou ao longo do século XIX, pois apesar de enfatizar as habilidades manuais e os dotes sociais, já era possível encontrar no currículo das escolas, desde meados da década de 1870, disciplinas tais como português, francês, inglês, aritmética, mitologia, etc. Registros da época asseguram que a educação feminina iniciava-se aos sete anos e terminava aos 14 com o casamento:

na Corte imperial, das meninas da alta sociedade, exigia-se perfeição no piano, destreza em língua inglesa $e$ francesa, $e$ habilidade no desenho, além de bordar e tricotar. (...) os filhos da elite rural e urbana foram advogados destacados, médicos distinguidos, engenheiros desbravadores do Império ou ainda políticos republicanos. [Enquanto isso] a educação das meninas, padecia de ambigüidade, pois ao mesmo tempo em que as circunscrevia ao universo doméstico, incentivando-lhes a maternidade $e$ estabelecendo o lar como seu domínio, as habilitava para a vida mundana, fornecendo-lhes elementos para brilhar em sociedade. ${ }^{64}$

A literatura de cunho moralista era utilizada então como um dos instrumentos para evitar os danos que poderiam ser ocasionados por esta ambivalência. ${ }^{65}$

A esse respeito, Santos comenta que

no ano de 1898 começava a circular em São Paulo uma revista chamada Álbum das Meninas. Com teor literário e

${ }^{64}$ MAUAD, A. M. A vida das crianças da elite... Op. cit., pp.154-155.

${ }^{65}$ ID., IB., pp.148-152. 
Luzinete Simões Minella

educativo, procurava iniciar as jovens leitoras no universo da arte, da literatura e da boa educação, trazendo artigos que as encaminhassem $e$ orientassem para o ingresso na vida adulta. ${ }^{66}$

Paralelamente, várias dificuldades eram enfrentadas pelos meninos pobres, conforme demonstram os resultados da pesquisa de Venâncio sobre o recrutamento de marinheiros no Brasil. Inicialmente afirma o autor, este recrutamento

incidia sobre três grupos: os enjeitados nas casas dos expostos, os enviados pela polícia e os "voluntários" matriculados pelos pais ou tutores". [A partir de 1840, a novidade] consistia no fato de os meninos receberem gratuitamente um enxoval $e$, no caso dos voluntários, os respectivos responsáveis ganharem o "prêmio" de cem mil reais; valor nada desprezível pois representava aproximadamente $20 \%$ do preço de um escravo adulto ou que permitiria a compra de duas ou mais crianças escravas. [Além do mais] os aprendizes que não se adaptassem à vida marítima podiam ser transferidos para as companhias de artífices, onde se especializavam nos ofícios de torneiros, ferreiros, carpinteiros e nos demais que fossem necessários à construção das embarcações, [tornando-se] uma das raras opções de ascensão social para os filhos dos forros ou de negros livres. ${ }^{67}$

Num contexto de pobreza urbana, essas companhias "representavam uma ruptura fundamental em relação ao atendimento dos meninos pobres maiores de sete anos de idade", que já não podiam permanecer nos hospitais ou na companhia de seus responsáveis. No entanto, afirma o autor,

${ }^{66}$ Santos, M. A. C. Criança e criminalidade... Op. cit., p.211.

${ }^{67}$ VENÂNCIO, R. P. Os aprendizes da guerra. Op. cit., pp.199, 200. 
História Social sobre infância no Brasil

"a vida nos estaleiros era rude". Regidos pelo castigo físico e recebendo uma alimentação precária, os meninos aprendiam natação, recebiam instruções sobre artilharia $e$ infantaria, eram alfabetizados, aprendiam a coser $e$ a remar. ${ }^{68}$

Nos períodos de guerra a legislação sobre alistamento permitia inclusive que fossem convocados entre nove e onze anos: "as leis que regiam as companhias são indício da ambição do recrutamento. Elas, por exemplo, não eram claras quanto à idade $e$ ao status desses garotos; afirmava-se que

os aprendizes marinheiros devem ser cidadãos brasileiros de 10 a 17 anos de idade; [em seguida adiantava-se a seguinte ressalva] poder-se-á também admitir menores de dez anos que tenham suficiente desenvolvimento físico para os exercícios do aprendizado. E, pior ainda, os textos legais destinavam os mesmos alojamentos para os carentes $e$ delinqüentes, dando origem a uma prática institucional perversa, na qual os estabelecimentos que acolhem crianças pobres acabam se transformando em escolas de crime. ${ }^{69}$

Segundo o estudo de Moura, tampouco era fácil a vida das crianças operárias. Embora admita que é difícil conhecer exatamente a origem dessas crianças, em particular na cidade de São Paulo, estima-se que 15\% do total da mão-de-obra absorvida pelos estabelecimentos industriais nas primeiras décadas do século $\mathrm{XX}$ eram crianças e adolescentes. Nesse caso, as hierarquias de classe se mesclaram com as hierarquias de gênero em benefício do capital:

entre os menores, as diferenças de salário também não eram desprezíveis, relacionadas não somente à idade, mas também ao sexo, refletindo claramente o mundo dos

${ }^{68}$ ID., IB., pp.198-199.

${ }^{69}$ ID., IB., p. 198. 
Luzinete Simões Minella

adultos. Predominava a política de pagar salários menos significativos aos trabalhadores mais novos, bem como às meninas e às adolescentes, apesar de algumas exceções. ${ }^{70}$

De acordo com os dados estatísticos levantados pela autora, $15 \%$ do total da mão-de-obra absorvida pelos estabelecimentos industriais eram constituídos por crianças e adolescentes. Os anúncios de empregos publicados nos jornais contribuem para esclarecer sobre a importância desse segmento:

no jornal Fanfulla, de língua italiana, uma vez concretizada a imigração de massa, palavras como bambini, fanciulli, ragazzi, minorenni, nos anúncios em busca de trabalhadores, tornavam pública a mensagem do empresariado, no sentido de que as portas das oficinas, os portões das fábricas, estavam de fato abertos para crianças e adolescentes. ${ }^{71}$

Finalizando, no outro extremo do país, as diferenças advindas da condição de classe entre as meninas em particular, chama a atenção no início do século XX. Rastreando os relatos de alguns literatos que passaram a infância $e$ a adolescência na Amazônia nas primeiras décadas deste século, Figueiredo reflete sobre os modelos de conduta impostos às meninas:

se algumas meninas da elite local vestiam-se à moda parisiense, outras meninas vindas do interior como "crias" dessas mesmas famílias mais ricas, tinham além de um traje diverso, outro espaço destinado à sua sociabilidade. Quando se rebelavam ou davam um "passo errado", cresciam em torno delas as acusações de que eram "adoráveis" crianças, mas que guardavam por trás dessa face inocente, a marca precoce de mulher "dissimulada". ${ }^{72}$

\footnotetext{
${ }^{70}$ MourA, E. B. B. Crianças Operárias... Op. cit., p.273.

${ }^{71}$ ID., IB., p.262.

${ }^{72}$ Figueiredo, A. M. Memórias da Infância na Amazônia. Op. cit., p.339.
} 
História Social sobre infância no Brasil

Nos espaços públicos, os rapazes podiam circular juntos. De acordo com a autora, filhos de criadas e filhos das elites desfrutavam juntos das festas religiosas, do carnaval e da escola. As meninas mais ricas estavam sempre acompanhadas pelas suas mães, pais e/ou acompanhantes, dedicando-se às atividades domésticas ("varrer a casa, encher o pote de água, arrumar a mesa", etc.) como uma extensão das brincadeiras.

\section{III - Considerações finais: engendrando a infância na História}

As considerações finais sobre os relatos históricos acerca do cotidiano da infância no Brasil, partem de retomar algumas das questões relacionadas no primeiro item desse artigo, com a preocupação centrada nas possibilidades de novas leituras que resultem da influência das reflexões feministas e de gênero a respeito da produção do conhecimento.

Do ponto de vista metodológico, vale lembrar que o enfoque dessa pesquisa se inspirou, dentre outras/os autoras/es, em Jane Flax, quando ela afirma que para entender o gênero como relação social, as teorias feministas precisam desconstruir e/ou desnaturalizar "os significados que damos a biologia/sexo/ gênero/natureza" ${ }^{73}$ Além disso, duas recomendações cruciais, feitas por Scott orientaram esse enfoque: primeiro, que devem ser pesquisadas as multiplicidades de causas da diferenciação entre masculino e feminino, evitando-se a busca de causas únicas, gerais, universais. Segundo, que deve-se indagar como funciona o gênero em sociedades concretas, observando-se as complexidades dos processos locais, evitando-se atribuir ao conceito de poder um sentido unificado e centralizado, admitindo por um lado, a existência de relações desiguais, constituídas pelos discursos elaborados nos "campos de forças sociais" $e$, por outro, as possibilidades de resistência, de invenção, de imaginação.

${ }^{73}$ FLAX, J. Pós-Modernismo... Op. cit., p.238. 
Considerando que gênero é um "elemento constitutivo de relações sociais fundadas sobre as diferenças percebidas entre os sexos" e ainda, que gênero não é o único, mas o primeiro campo "por meio do qual o poder é articulado", Scott sugere que as significações de gênero e poder se constituem reciprocamente, importando saber como vão se modificando em situações específicas. Torna-se, portanto, indispensável analisar aspectos tais como símbolos, conceitos normativos, instituições, organizações sociais e políticas na proporção em que moldam a identidade subjetiva. $^{74}$

A leitura das informações contidas nos relatos históricos também levou em conta o ponto de vista de Machado sobre a metodologia desconstrucionista, que,

aliada à crítica foucaultiana do poder, à hermenêutica e à descrição densa, tal como elaboradas e combinadas pelas pesquisas de gênero e pelas pesquisas feministas, foi capaz de produzir a desnaturalização metodológica do gênero. $\mathrm{O}$ desconstrucionismo tal como foi empregado pelos estudos de gênero, mas no quadro de uma postura feminista se revelou como uma empresa cultural e teve efeitos de empresa cultural de crítica à naturalização de gênero. ${ }^{75}$

Nessa perspectiva de desconstrução, observei que os estudos analisados, ao referirem-se aos meninos e meninas, adotaram uma perspectiva polarizadora, centrada nas referências ao desempenho dos papéis sexuais institucionalmente esperados e estimulados pelas instituições familiares, educacionais $e$ assistenciais. Não obstante tais limites, esses estudos fornecem informações preciosas e pistas relevantes que contribuem para compreender como, no caso particular da sociedade brasileira, gênero e poder/saber se constituíram reciprocamente, atribuindo-

${ }^{74}$ ScotT, J. Gênero: uma categoria útil... Op. cit., pp. 14 e 15.

${ }^{75}$ MaChado, Lia Zanotta. Gênero: um novo paradigma? Cadernos Pagu (11), Núcleo de Estudos de Gênero - Pagu/Unicamp, 1998, p.125. 
História Social sobre infância no Brasil

se ao feminino um papel secundário e complementar ao masculino. Os aspectos do cotidiano regularmente abordados são a educação e a formação religiosa, o trabalho, as regras de sociabilidade e a marginalidade, além dos jogos e brincadeiras. Ainda que tais estudos não explicitem as razões dessa ênfase, terminam por revelar não uma criança e uma infância universais, essenciais, mas uma multiplicidade de crianças e de infâncias, que variam conforme o contexto analisado, diante da riqueza e dos limites das próprias fontes consultadas pelos/as pesquisadores/as.

Os estudos analisados revelam - através de consultas a inúmeros documentos históricos (cartas, diários, atas de instituições, etc.) -diferentes maneiras através das quais as mais distintas instâncias sociais, núcleos familiares, educadores, instituições de assistência administradas por religiosos e irmãs de caridade, patrões, tribos indígenas e classes sociais, impulsionaram o processo de socialização de meninos e meninas a partir de representações que podem ser interpretadas como fundadas no sexo, e que são potencializadas pelas dimensões de classe e de etnia. Dessa forma, retomando os pressupostos iniciais da análise, foi possivel perceber que tais instâncias desenvolveram saberes $e$ definiram estratégias de poder sobre a infância a partir de uma lógica da identidade, permitindo-se diagnosticar situações, desenhar perfis, identificar, isolar, segregar e/ou integrar, projetando o futuro de meninos e meninas conforme as expectativas e os padrões de comportamento que vigoravam na época: as meninas pobres, os afazeres domésticos, ou em menor escala, o trabalho nas fábricas, e/ou, ainda, a segregação; às meninas da elite, a educação doméstica refinada e o incentivo à música e à leitura; aos meninos pobres, o desempenho dos ofícios e/ou a segregação; aos meninos da elite, a educação formal e as "habilidades superiores".

Tais polarizações, de forte cunho identitário e essencialista, remetem a outro dos pressupostos iniciais da análise inspirado em Flax: os relatos mostram que as relações de gênero foram construídas também enquanto divisões $e$ atribuições distintas $e$ 
assimétricas das capacidades humanas, que foram fortemente introjetadas pelos mecanismos de socialização durante a infância.

Joan Scott colabora ainda para compreender as evidências a respeito dos saberes institucionais sobre o gênero, encontrados e/ou inferidos nas práticas narradas pelos estudos analisados quando observa que

os usos e significados dos saberes sobre o gênero, nascem de uma disputa política e são os meios pelos quais as relações de poder - de dominação e de subordinação - são construídas. $\mathrm{O}$ saber não se refere apenas à idéias, mas a instituições e estruturas, práticas cotidianas e rituais específicos, já que todos constituem relações sociais. O saber é um modo de ordenar o mundo, e como tal, não antecede a organização social, mas é inseparável dela. ${ }^{76}$

Ao se referirem aos papéis, espaços $e$ atribuições de meninos e meninas, independentemente da classe, da etnia, e até mesmo do período analisado, boa parte dos registros históricos, remetem a uma associação, às vezes não muito clara, do masculino à esfera pública e do feminino à esfera privada, sugerindo que esse cotidiano revela a rigidez das regras do comportamento, inclusive no âmbito dos jogos e brincadeiras. Também se torna possivel perceber que tais registros apontam mais para as regularidades dos comportamentos do que para dispersões e descontinuidades, fato que talvez se explique em função das dificuldades de identificar os "desvios", através das fontes utilizadas.

Chama particularmente a atenção, a dificuldade de encontrar trabalhos que colocam as meninas no foco central de investigação. Dentre os vários estudos citados, apenas Abreu ${ }^{77}$ coloca a problemática das meninas no centro da análise. Na maior parte das vezes, as informações sobre elas aparecem após páginas

${ }^{76}$ SCOTT, J. Prefácio a Gender and Politics of History. Op. cit., pp.12 e 13.

${ }_{77}$ ABREU, M. Meninas perdidas... Op. cit. 
História Social sobre infância no Brasil

e páginas de referências aos meninos. Certamente, são múltiplas as razões dessa relativa invisibilidade, mas destaco três prováveis: em primeiro lugar, os meninos parecem ter sido o alvo preferencial de intervenção institucional, daí que talvez seja mais viável a identificação de fontes que registraram mais regularmente seu cotidiano. Em segundo lugar, eles também tiveram acesso "privilegiado" à educação (tanto religiosa quanto formal) e ao trabalho fora do espaço doméstico, conseqüentemente, é possível que o número de registros sobre seu cotidiano seja maior do que sobre o das meninas. Em terceiro lugar, embora os historiadores e historiadoras tenham produzido extraordinários avanços sobre o tema, permaneceram marcados/as tanto por sua época, quanto por seu lugar social, destacando certos aspectos e silenciando outros em função dessas instâncias de localização. Por isso mesmo, os estudos citados não refletem uma atitude crítica a respeito da invisibilidade das meninas nas fontes consultadas, (mesmo que tenham sido elaborados por mulheres, como ocorre em muitos casos), o que leva a pensar que talvez tenha prevalecido um certo androcentrismo por parte dos/as pesquisadores/as, como se o fato de terem encontrado mais referências aos meninos do que às meninas fosse natural.

A relativa invisibilidade das meninas e a ausência de crítica às fontes remetem a algumas das contribuições teóricas sistematizadas no início desse estudo, por exemplo, ao ponto de vista de Foucault a respeito das disciplinas como instâncias de verdades e erros que têm (ambos) uma eficácia histórica; ao argumento de Harding sobre a necessidade da crítica feminista refletir acerca daquilo que a ciência deixa de dizer $e$ às advertências de Lauretis no sentido de que a construção de gênero também se faz na Academia.

Finalizando, ressalto que tampouco foram encontradas críticas ao visível e rígido processo de sexualização dos papéis sociais que aparece nos registros, tendo observado que, de modo geral, as desigualdades e os estereótipos de gênero que podem ser inferidos a partir daí não chegam a ser de fato interpretados. 
Posso afirmar que os estudos dizem mais sobre meninos e menos sobre meninas, abstraindo a dimensão das relações de gênero, embora os seus achados possam ser lidos através das possibilidades abertas pela epistemologia feminista e pela perspectiva de gênero. 